\title{
CRIAÇÃo DE CHAVE DE INTERATIVA: UMA ALTERNATIVA PARA IDENTIFICAÇÃO E ENSINO DE BOTÂNICA CRIPTOGÂMICA
}

\author{
Angélica Tomazeli da Silva ${ }^{1}$ \\ Thamara Arão Feletti ${ }^{2}$ \\ Juliana Rosa do Pará Marques de Oliveira ${ }^{3}$
}

Resumo: A botânica, seja pelo número elevado de organismos estudados, complexidade de conceitos e termos específicos ou ainda, pela falta de contextualização em que é comumente ensinada, é apontada como uma das mais "difíceis", tanto na educação básica como no ensino superior. O objetivo deste trabalho foi produzir uma ferramenta didática interativa que contribuísse com o ensino de botânica criptogâmica, tanto no ensino médio quanto no superior. Para isto foram coletadas espécies de musgos no Parque Nacional do Caparaó, e estas foram identificadas e descritas, totalizando 31 espécies de musgos, que foram inseridas na plataforma Xper3. Também na plataforma foram inseridos 32 caracteres morfológicos de identificação. A partir disto, construiu-se a chave de identificação interativa, que após finalizada, será publicada on line para que todos possam ter acesso. Desta forma, será uma ferramenta didática que poderá ser utilizada para melhorar de forma significativa o ensino de botânica, ensino de taxonomia e identificação, visto às grandes dificuldades relatadas por alunos e professores, particularmente na identificação de material botânico.

Palavras-chave: Educação; Recurso didático; Briófitas; Musgos; Identificação.

\footnotetext{
1 Ciências Biológicas/Universidade Federal do Espírito Santo, Brasil. E-mail: angelicatomazeli.bio.2012@gmail.com.

2 Ciências Biológicas/Universidade Federal do Espírito Santo, Brasil. E-mail: thamarafeletti8@gmail.com.

${ }^{3}$ Departamento de Biologia/Universidade Federal do Espírito Santo, Brasil. E-mail: julianabio2@yahoo.com.br.
} 